\title{
EN TORNO A LA NOCIÓN DE POBREZA VOLUNTARIA
}

\author{
Ignacio Salazar \\ Universidad de Sevilla
}

Quizá pudiera pensarse que el tema de la pobreza voluntaria pueda tener ahora una vigencia mayor que hace tan solo dos o tres años.

Quizá, en algún rincón de nuestra sensibilidad, la perspectiva de un enriquecimiento sin límites nos produzca un cierto escalofrío, y puede que nos sintamos un tanto huérfanos, sociológicamente hablando, a la hora de buscar razones para la contención consumista. Ante la pendiente sin fondo del consumo total parece que no tenemos más que el volante de nuestro sentido común, y el freno de nuestro instinto de austeridad.

Haya o no algo de verdad o de actualidad en la sensación descrita, quizá pueda tener algún - interés recordar algunas vicisitudes aparejadas históricamente a una noción tan singular como la de «pobreza voluntaria».

Yo voy a ceñirme aquí, siguiendo la a mi juicio magnífica obra de Lester $\mathrm{K}$. Little, a la historia de la pobreza voluntaria en el occidente cristiano entre las fechas aproximadas del año 1000 y 1300 , tal y como se relaciona con la nueva economía del beneficio.

Las principales preguntas que se plantea este autor son las siguientes:

- ¿Por qué los cristianos latinos reaccionaron como lo hicieron ante el desarrollo de una economía del beneficio en el inicio del segundo milenio cristiano?

- ¿Por que las relaciones entre cristianos y judíos se desintegraron tan desastrosamente en los siglos XII y XIII?

- ¿Por qué se convirtió la pobreza voluntaria en el elemento clave de las formas renovadas de la vida religiosa?

- ¿A qué es debido que los que eran voluntariamente pobres desarrollaran una ética justificando las actividades lucrativas de los mercaderes y los profesionales urbanos? ${ }^{1}$

Nosotros aquí no vamos a decir nada de la segunda cuestión, y resumiremos algunas ideas acerca de las otras tres.

1 Little, L.K., Pobreza voluntaria y economía de beneficio en la Europa medieval, Taurus, Madrid, 1983, p. 7. 
Según los especialistas, ${ }^{2}$ hay dos edades feudales de tonalidades muy diferentes, siendo la separación hacia el año 1050.

Durante la primera edad feudal la economía de regalo floreció en los siglos que siguieron a las migraciones germánicas. En una economía del regalo, los bienes y servicios se intercambian sin que se les asigne unos valores específicos calculados. El prestigio, el poder, el honor y la riqueza se expresa en la entrega espontanea de regalos. El acto de dar es más importante que la cosa dada, si bien un regalo obliga al receptor a devolver a cambio otro regalo.

La primera edad feudal es un diálogo entre los pueblos germánicos recientemente establecidos, principalmente cristianos y ligeramente romanizados de Europa occidental, y sus atacantes no cristianos: los vikingos, los magiares, y los musulmanes.

Hacia mediados del siglo XI, Europa se encontró finalmente libre de los ataques de pillaje de extraños. Toda la Europa latino-cristiana fue capaz a partir de entonces de vincularse a un sistema de mercado de intercambio donde el dinero servía como un modelo de valor para los artículos que se intercambiaban.

La segunda edad feudal, que coincidiría con la fundación de las principales ciudades entre 1050 y 1320-30 constituiría el auge de la cristiandad. En esta época la esplendidez no desapareció, como tampoco lo hizo el saqueo, pero se constata la aparición de una actitud totalmente diferente, que calculaba el valor para ver si una actividad o transacción particular podría traer beneficios. Esto es consecuencia de la promoción del comercio y la industria desde su status de actividades marginales hasta el nivel de elementos claves en la vida económica europea. Finalmente, se produjo el reconocimiento y uso del dinero como instrumento en lugar de como tesoro, la puesta en circulación de nuevos tipos y de bastas cantidades de numerario, y la aparición de nuevas técnicas para su manejo expeditivo. ${ }^{3}$

\section{ADAPTACIÓN A LA ECONOMÍA DE BENEFICIO}

El avance de la nueva economía tuvo repercusiones prácticamente en todas las instituciones, grupos sociales, areas geográficas y núcleos ideológicos de la Cristiandad latina.

Uno de los problemas principales a que dio lugar tenía relación con el tamaño de las comunidades en las que vivía la gente y con el número y tipo de individuos con quienes trataba. El cambio cuantitativo de la población trajo con sigo cambios cualitativos en la vida humana.

Un segundo problema correspondió a los tipos de trabajo realizados y a la naturaleza de recompensas que recibía a cambio. La introducción de transacciones monetarias, anteriormente muy restringidas, en casi todas las relaciones y en la mayoría de las areas de actividad dio lugar a conflictos entre los individuos y entre las instituciones.

2 Le Goff, J., La baja edad media, Siglo XXI, Madrid, 1986, p. 6.

3. Little, L.K., Ob. cit. p. 32-33. 
Y apareció un tercer problema producto de lo obsoleto de la moral cristiana dominante. Para cierta gente fue difícil adaptarse a una nueva realidad social y económica cuando su religión interponía una moralidad claramente articulada y sancionada por Dios, propia de una etapa anterior. De este modo la vida en la nueva economía del beneficio originó problemas espinosos que implicaban pérdida de personalismo, dinero e incertidumbre moral. ${ }^{4}$

En la segunda edad feudal, el principal tema moral era que el ejercicio de las principales profesiones urbanas, como el dinero en sí mismo, era simultáneamente buscado y despreciado. La tradición recibida estaba de hecho predispuesta contra todos los elementos principales de la nueva economía: contra las ciudades, contra el dinero y contra las profesiones urbanas.

Hasta finales del siglo $X$ la vanidad había sido sin duda el vicio dominante. Los escritores que trataban la avaricia la reducían a una subcategoría de la vanidad. Pero en el siglo XI, Pedro Damián anunció un cambio significativo cuando afirmó que «la avaricia es la raíz de todo mal».5

Juan de Salisbury, Alain de Lille, San Bernardo escriben contra la avaricia. El planteamiento satírico del poder corrosivo del dinero estuvo plenamente vigente a comienzos del siglo XII.

Pedro Lombardo también reiteraba que los mercaderes no pueden cumplir sus tareas sin pecar.

La presencia cada vez mayor de usureros en las ciudades a partir del siglo XI en adelante inspiró abundantes condenas morales sobre el préstamo de dinero acumuladas desde los tiempos de Moisés.

El concilio de Tours de 1163 condena el préstamo con interés, que es asimilado a la usura, e incluso el empeño. ${ }^{6}$

Los padres del Tercer Concilio Laterano (1179) indicaron que la usura estaba floreciendo prácticamente en todos los lugares como si se tratase de una empresa lícita.

Los maestros que enseñaban en las escuelas de la ciudad así como los abogados tuvieron que hacer frente al dilema de si tenían derecho a vender el conocimiento, cuando la tradición enseñaba que el conocimiento era un regalo de Dios, y que por tanto no puede ser vendido.

En este ambiente se explica la súbita popularidad en el siglo XII de una historia muy antigua conocida por «Vida de San Alejo»: Cuento popular que tenía dos temas nuevos bastante específicos:

- El de la renuncia voluntaria a la riqueza.

- La adopción de la mendicidad religiosa, que hasta entonces había sido exclusivamente una practica oriental.

La exaltación de la leyenda de un hombre pobre por su voluntad se combina con:

1) Las advertencias moralistas contra la perversidad de la vida en la ciudad y el carácter sórdido de la gente que en ella se reunía.

2) Las desgracias que podía traer el dinero.

3) Los relatos de corrupción en prácticamente todas las instituciones, incluyendo las más sagradas de la sociedad.

4 Ibidem, p.34. Véase también Vauchez, A.; La espiritualidad medieval, Cátedra, Madrid, 1985, p.66.

5 Little, L.K., Ob. cit. p. 55.

6 Vauchez, A., Ob. cit. p. 95. 
4) Las denuncias de teólogos y canonistas de la deshonestidad virtualmente inevitable de los mercaderes.

5) Las prohibiciones de prestar dinero.

6) Las serias dudas acerca de la legitimidad de los honorarios profesionales.

7) Las advertencias gráficas contra los peligros morales de prestar dinero.

Todos estos elementos juntos sugieren la tensión que se desplegó entre los sectores innovadores de la segunda edad feudal y la moralidad heredada de la época anterior. Tan intransigente era esa moralidad que prácticamente cualquier participación en los niveles superiores de la economía comercial implicaba los peligros del pecado y conjuraba los peligros de visiones aterradoras.

La adaptación a la economía del beneficio estuvo por tanto cargada de dificultades. Creó tensiones entre la moral y el comportamiento, entre la teología y la sociedad, entre la religión y la vida misma. ${ }^{7}$

\section{POSTURAS ANTE LA CRISIS}

Ante esta crisis, las respuestas disponibles, que eran naturalmente religiosas, pueden dividirse entre aquellos que rehuyeron la cuestión (Orden monástico antiguo, movimiento eremítico y comunidades monásticas reformadas) y aquellos que la afrontaron (canónigos, laicos, y frailes).

\section{- El Orden Antiguo}

El orden monástico estuvo establecido tan sólidamente, tanto material como espiritualmente, que la transición realizada por los monasterios de la economía del regalo a la economía del beneficio se hizo sin preocupaciones ni reflexiones.

A largo plazo, la aceptación irreflexiva de esta transición resultó costosa para el viejo orden monástico. ${ }^{8}$

\section{- El movimiento eremítico}

La vida eremítica no había tenido un papel continuo ni influyente en el Occidente cristiano. Aunque el ejemplo de los Padres del Desierto estuvo grabado en el pensamiento de los fundadores de monacato occidental, no apareció en Europa un movimiento eremítico floreciente hasta el siglo XI, precisamente en el momento en el que la nueva sociedad urbana estaba adquiriendo forma y el antiguo orden monástico alcanzaba su cima de poder y prestigio.

El movimiento eremítico constituyó un rechazo a las nuevas ciudades y a los antiguos monasterios. Evitó los problemas de las primeras y los compromisos de los segundos, en favor de un ideal basado en el modelo de los ermitaños egipcios. Al igual que el primer movimiento eremítico, el del siglo XI y XII condujo a un movimiento cenobítico reformado. ${ }^{9}$

7 Little, L.K., Ob. cit. p. 62.

8 Ibidem, p. 95. Véase, Vauchez, A., Ob. cit. p. 95.

9. Ibidem, p.112. Véase, Vauchez, A., Ob. cit. p. 79. 


\section{- Comunidades monásticas reformadas}

Los cartujos y los premostratenses, así como los cistercienses, ${ }^{10}$ florecieron en el siglo XII. $\mathrm{Al}$ intentar mantenerse lejos de la turbulencia de la vida de la ciudad, estas órdenes, al igual que el movimiento eremítico del que eran la obra acabada, desplegaron una sensibilidad hacia los problemas que emergieron por las nuevas circunstancias económicas y sociales. Pero no ofrecieron soluciones, sino que ayudaron a sus seguidores a evitar esos problemas. ${ }^{11}$

\section{EL CONFRONTAMIENTO DE LA CRISIS}

\section{- Canónigos}

Las respuestas religiosas a la economía del beneficio incluyeron movimientos firmemente establecidos en la propia sociedad urbana.

El primer confrontamiento religioso directo con esta sociedad vino con el programa de reforma de los canónigos regulares. Un programa que pretendía convertir al clero secular, muchos de cuyos miembros vivían «more laicorum», ${ }^{12}$ en algo claramente diferenciado del laicado.

La clave de esta reforma del sacerdocio era la pobreza individual y la vida en común junto con un activo apostolado. ${ }^{13}$

\section{- Laicos, Humillados, Valdenses, Beguinas y Cátaros}

Una segunda confrontación fue la organizada por varios grupos de laicos que buscaban un significado más profundo fuera de las formas establecidas de la vida religiosa. Su denominador común era la pobreza voluntaria. ${ }^{14}$

Lo que muchos de estos tuvieron en común fue el rechazo del nuevo materialismo, especialmente monetario, concretamente el que se hallaba en las instituciones eclesiásticas. Bien porque intentasen cooperar con la jerarquía clerical, cambiándola directamente, o porque meramente la evitasen, todos estos grupos tropezaron con la resistencia y hostilidad oficial.

Junto a ello, su explicitación de gran parte del dualismo implícito en la teología cristiana condujo a muchos de ellos más allá de la delgada línea que separa la ortodoxia de la herejía, poniendo de este modo en peligro su situación ya precaria. ${ }^{15}$

\section{- Frailes}

La orden franciscana y dominica completaron la búsqueda de una espiritualidad basada en la pobreza voluntaria.

10 Vauchez, A., Ob. cit. p. 86-87.

11 Little, L.K., Ob. cit. p. 127-128.

12 Vauchez, A., Ob. cit. p. 46.

13 Little, L.K., Ob. cit. p. 85.

14 Vauchez, A., Ob. cit. p. 89,90 y 93.

15 Little, L.K., Ob. cit. p. 131. 
Esta búsqueda había comenzado con los ermitaños italianos, y había sido parcialmente llevada a cabo en una $u$ otra forma por ciertas figuras y grupos religiosos de los siglos XI y XII.

Los frailes, en cierto sentido, combinaron las formas de sus predecesores en un programa espiritual coherente y practicable.

En el siglo XIII aparecieron otras ordenes mendicantes, pero los franciscanos y dominicos les superaron con mucho en volumen y eficacia. Estos hicieron algo más que reemplazar a humillados y valdenses. Sumaron y sintetizaron la reforma canónica y la nueva espiritualidad laica. ${ }^{16}$

El programa revolucionario de la predicación mendicante, que era un desafío a muchos intereses establecidos, se convirtió en un modo de reforma interna y metódica de la Iglesia a través de la destreza y la atenta dirección de Inocencio III y del cardenal Hugolino. La vida apostólica, que durante muchas generaciones había estado fuera o en los límites de la Iglesia, fue cautelosamente vuelta al redil; fue recuperada de la marginalidad.

Los frailes crearon nuevas formas de expresión religiosa específicas para el sector urbano de la sociedad y para aquellas personas que dominaban en él.

Estas nuevas formas incluían una justificación ética de la sociedad urbana en sí misma así como de las actividades características de sus miembros más influyentes. También incluían nuevas formas de culto, nuevas prácticas de devoción, nuevas estructuras para la participación laica en la caridad organizada, y sobre todo un acrecentado sentido del valor espiritual.

Los senderos por los que llegaron a este punto fueron intelectuales y pastorales:

Primero lograron una armoniosa integración de los últimos acontecimientos espirituales con el primer plano de la vida religiosa. La escolástica y la espiritualidad de los frailes estuvieron enteramente entrelazadas durante los dos cuartos centrales del siglo XIII.

Segundo, los logros intelectuales de los frailes y de sus contemporáneos llegaron a un inmenso auditorio más allá de las universidades a través de las nuevas técnicas de comunicación pastoral; técnicas que en muchos caso no inventaron los frailes, pero que sin embargo explotaron con gran destreza.

\section{LA FORMACIÓN DE UNA ESPIRITUALIDAD URBANA}

\section{- El pensamiento social escolástico}

Las escuelas de ciudad, o universidades como se las empezó a llamar en el siglo XIII, proporcionaron el marco para la actividad intelectual de los frailes.

Las escuelas habían roto el monopolio de la cultura y las educación superior mantenida durante mucho tiempo por los monasterios benedictinos. Maestros y estudiantes a tiempo, independientemente de su contexto social, se convirtieron en partícipes de un atareado modelo de vida urbana, teniendo que afrontar los problemas subsiguientes de apoyo económico, alojamiento lejos del hogar, tasas y honorarios.

16. Vauchez, A., Ob. cit. p. 108,110 y 120. 
El programa de la escuela urbana estaba basado en la polémica. Los monasterios y las escuelas eran tan opuestos en los métodos que utilizaban, como en sus asentamientos sociales y sus metas espirituales.

Los estudiosos urbanos, al tiempo que seguían respetando la tradición recibida, sacaban fuerzas de ella e intentaban exponer su debilidad para poder construir sobre ella, para poder llegar más arriba y ver más lejos. Esta noción de progreso se convirtió en una meta que alimentó a varias generaciones de maestros de escuela, al mismo tiempo que desanimaba y ultrajaba a los principales intelectuales monásticos.

Impávidos ante los ataque monásticos, los maestros de escuela afilaron sus armas e intervinieron en los aspectos más peliagudos de los problemas legales y teológicos. ${ }^{17}$

El derecho y la teología se encontraban en una coyuntura crucial de comportamiento humano y en la segunda mitad del siglo XII colaboraron para formar la sub-disciplina de la teología moral. La jurisprudencia, como le teología, se estaban convirtiendo en una ciencia. Abelardo fue la gran figura de este triunfo de la escuela en el siglo XII.

La verdadera primera escuela de teología moral se centró en París en las últimas décadas del siglo XII, donde se reunía una tertulia de intelectuales alrededor de Pedro el Cantor. Era el momento en que las crecientes necesidades de negociación y gobierno para un sistema crediticio entraban en conflicto con la rígida moral anticomercial.

Aunque se repitieron también algunos de los viejos clichés tan hostiles a la actividad comercial, comenzaron las cuidadosa investigación, punto por punto, de muchas actividades concretas relacionadas con los mercaderes y los profesionales urbanos. Al final, de ningún modo aprobaron todas estas actividades, pero prepararon el camino para la justificación espiritual de los mercaderes y profesionales que los teólogos del siglo XIII iban a desarrollar.

De este modo, el escenario educativo al que llegaron los frailes poco antes de 1220 estaba dominado por la escuela urbana, una institución donde se utilizaba la gramática y la lógica para referirse al derecho y a la teología, y donde teólogos y abogados dedicaban gran parte de su esfuerzo a investigar y resolver problemas sociales de su momento histórico.

Así como los antecedentes de la espiritualidad de los frailes puede rastrearse en grupos tales como los ermitaños, los canónigos regulares, los valdenses y los humillados, no parece, sin embargo, que estos grupos hayan dejado a los frailes ningún legado intelectual especial. La herencia intelectual de los frailes provino, por el contrario, de las escuelas del siglo XII y en particular de estudiosos como Pedro el Cantor y asociados.

Los frailes no fueron inventados para servir las necesidades de las escuelas, ni tampoco las escuelas, al proporcionarles un programa intelectual, fueron creadas para servirles. Las escuelas urbanas y los apóstoles urbanos, después de un período de desarrollo independiente, formaron una poderosa coalición a finales del primer tercio del siglo XIII. Entre los principales problemas tratados por los frailes se encontraba la propiedad privada, el precio justo, el dinero, los honorarios profesionales, los beneficios comerciales, los modelos de negocios y el préstamo de dinero. En cada caso se presentaron con opiniones generalmente favorables y de

17 Little, L.K., Ob. cit. p. 216. 
aprobación, en agudo contraste con las actitudes que habían prevalecido durante seis o siete siglos hasta la generación anterior.

Aristóteles proporcionó a los escolásticos toda una teoría completa de la utilidad social. Con esta teoría, Alberto Magno, Tomás de Aquino, Alejandro de Hales, Buenaventura y otros labraron la emancipación de los mercaderes cristianos. ${ }^{18}$

Así, al orientarse las enseñanzas escolásticas hacia un cuidadoso examen de los problemas sociales, se preocuparon por ofrecer una guía para vivir en medio -en lugar de lejos- de las realidades sociales. La conducción de estas enseñanzas desde las universidades hasta los cristianos laicos supuso un importante esfuerzo espiritual y organizativo.

Al igual que los cluniacenses que en tiempos habían sido insultantemente llamados soldados y descritos con trajes militares y armados de sus espadas, sus lanzas y sus yelmos, los franciscanos y dominicos, eran análogamente denunciados por su avaricia, su riqueza, sus tratos comerciales y sus negocios: en suma por su parecido con los mercaderes.

De igual manera que los monjes se enfrentaron al principal problema de la sociedad feudal, a saber, la violencia, ${ }^{19}$ los frailes debieron enfrentarse al principal problema de la nueva sociedad, es decir, la acumulación del dinero.

En primer lugar rechazaban la acumulación del dinero para sî mismos, y en cambịo se entregaban al ideal, de reciente madurez, de la pobreza voluntaria.

En segundo lugar, sin embargo, mantenían los modos lingüísticos y formales de los señores del dinero, aunque evitando los aspectos espiritualmente nocivos de la actividad de dichas gentes.

En tercer lugar, una vez que habían demostrado pertenecer ellos mismos al medio, proporcionaban a los líderes de la sociedad urbana una teología moral revisada que aprobaba la acumulación de dinero en ciertas circunstancias cuidadosamente definidas. La espiritualidad de los frailes estaba determinada por la nueva sociedad urbana, y al mismo tiempo era un factor determinante de ella. ${ }^{20}$

Así, paradójicamente, ya en la Pisa de 1261, San Francisco de Asís, el más insigne de los .pauperes Chisti», se había convertido en el patrón y protector de los mercaderes. ${ }^{21}$

18 Ibidem, pp. 221-222.

19 Vauchez, A., Ob. cit. p. 61.

20 Little, L.K., Ob. cit. p. 249.

21 Ibidem, p. 267. 